\title{
The aesthetic of fish scale Texture patterns as textile Designs embellishments
}

\author{
Rusmawati Ghazali $^{\text {a,d }}$, Maithreyi Subramaniam ${ }^{\text {b }}$, Sabzali Musa Kahn ${ }^{c}$, \\ Rainal Hidayat Wardi ${ }^{\text {, }}$ Irma Murni Ismail ${ }^{\text {, }}$, Syed Muhammad Ahmad Sherazi ${ }^{\mathrm{e}}$.
}

\begin{abstract}
The aesthetic of fish scale texture pattern as a textile designs embellishments are employed as an artistic substance in textile design. There are four types of fishes that can be found in the seas of Malaysia, namely Thread Fish Bream, Herring, John Snapper and Malabar Red Snapper. They are of various shapes and sizes, shiny, weight and texture. The four distinct kinds of fish scales being investigated had proved to be of distinct dimensions, shapes and textures. Fish scales such as Placoid scales, Ganoid's scales, Cycloid scales and Ctenoid scales were used to study its aesthetic qualities. In this study, the researchers have analyzed the aesthetic qualities of the four fish scales in terms of Clive Bell (1914/2014) and Roger Fry (1920/2011) formalism theory thought that formal aesthetic features of the fish scales are determined by the lines, shapes, form, texture and varieties. The findings showed that the Malabar Red Snapper has the thickest scales. The John Snapper has a texture that looks like a fingerprint and the scales of Herring has an interesting surface. It has contour lines. Its scales are also attractive because the edge produces furry lines after the drying process. Fish scales also have their own unique characteristics. They can be smooth and flat when water is spread over and become hard and rolled under the sunshine. Then, the fish scales are smoothen again when water is spread over and vice versa. Hence, this study serves as an artistic identity and determine the textile designs recognition.
\end{abstract}

Index Terms-Aesthetic, Fish Scales, Texture, Pattern, Textile Design Embellishments

Revised Manuscript Received on July 05, 2019.

Rusmawati Ghazali

Ph.D Student, Cultural Centre, University of Malaya, 50603

Kuala Lumpur, Malaysia

Maithreyi Subramaniam

Lecturer, Department of Advertising, journalism\& General

Electives Xiamen University Malaysia.

Sabzali Musa Kahn

Senior Lecturer at Academy of Malay Studies, University of

Malaya, Kuala Lumpur, Malaysia

Rainal Hidayat Wardi

Senior Lecturer in Textile Design Department, Faculty of Art

\& Design, Universiti Teknologi MARA, Malaysia

Irma Murni Ismail

Senior Lecturer, Universiti Teknologi Mara (UiTM), Shah

Alam, Malaysia

Syed Muhammad Ahmad Sherazi

Independent Researcher, S Rose Hotel Sepang Selangor

Malaysia

\section{INTRODUCTION}

The implementation of textile embellishment has always been in conflict with the result of consciousness that can trouble artistic determinations. This study investigates the Fish Scales as the suggested alternative media context material. Design manipulation is composed of the thoughtful progression that has been significantly obtained for the artistic appearances of appropriate sensitivity growth. In terms of growth of textile models, the result of compelling and artistic sensitivity should be equipped. The unwanted substances will occur in some respects and have caused the issues of barriers.

The necessary result should be included with a multitude of relevant patterns from the creations of the creative elements.In many respects, the surface can also be ornamented with anticipated design patterns to improve textile appearances.As for the consequence, surface embellishments required aesthetic appreciation for the unique determination and values added in the field of art and design. Fundamentally, the entire guideline reflected in formalism theory that was implemented to study the visual appearance of fish scales that can be used as an alternative surface prospect.This research can serve as an artistic identity and determine recognition of textile designs.

\section{RESEARCH BACKGROUND}

The rising of the important design knowledge and artistic sentiment has relatively acquired research on the textile designs demand. Aesthetics are found as a pleasure gained from sensory perception, most suitable in that it evidently divides aesthetic phenomena from other kinds of experience, such as the construction of meaning and emotional responses (Hekkert, 2006).

\section{RESEARCH OBJECTIVES}

In exploring the aesthetic of fish scale texture, pattern, the researchers have highlighted three important objectives related to this study, namely:

To identify the aesthetic of fish scale texture patterns as

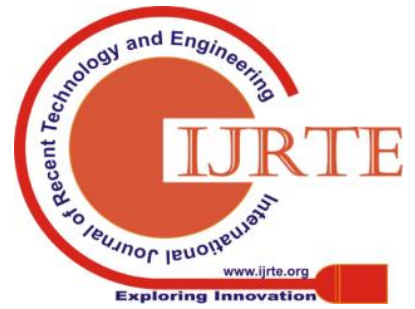




\section{THE AESTHETIC OF FISH SCALE TEXTURE PATTERNS AS TEXTILE DESIGNS EMBELLISHMENTS}

(ii) To investigate the formal aesthetic features such as lines, shapes, form, texture and varieties.

(iii) To explore the formalism theory through the study of fish scales.

\section{Theoretical Framework: THE PURPOSES AND FUNCTIONAL}

The researchers used formalism theory to explore aesthetic recognition of the texture pattern of fish scales as textile embellishments.

\section{(a) Formalism Theory}

The main notions for both Bell (1914/2014) and Fry (1920/2011) are aesthetics, only "significant form" must be studied as the soul of visual art forms. It is believed that through significant form, one can assess the art since it can clarity the peculiar nature of an aesthetic experience which it represents the autonomy of work of arts (as cited in Braembussche, 2009). Braembussche also emphasized that Bell and Fry's theory of significant form is similar to the contemporary view that visual art is concerning the artistic process that is often related to formalism, technical and aesthetic property of work of arts. Both art critics believe that the elements like lines, shapes and colours govern the formal quality of works of art.

Formalism is predominantly an examination about what it takes to determine the aesthetic characteristics or features or properties of things that incorporate the elements and principles of art. "Aesthetic" is an approach to give a sense of the features that are aesthetic like: beauty, ugliness, daintiness, dumpiness, elegance, and etc. Formalist theory emphasizes meaning that is intrinsic in the formal qualities of a work of art.

Bell (1914/2014) explains that to appreciate works of art it has to be related to the experience from our past, the knowledge that we have and emotion can influence an individual interest. The only internal or intrinsic criteria are considered important for the formalists, which are the forms (elements and principles of art) of the work of art and not the content. This is because the judgment of work of arts can be merely based on the formal properties (as cited in Braembussche, 2009). Below is the theoretical framework used in this study (Refer to Figure 1).

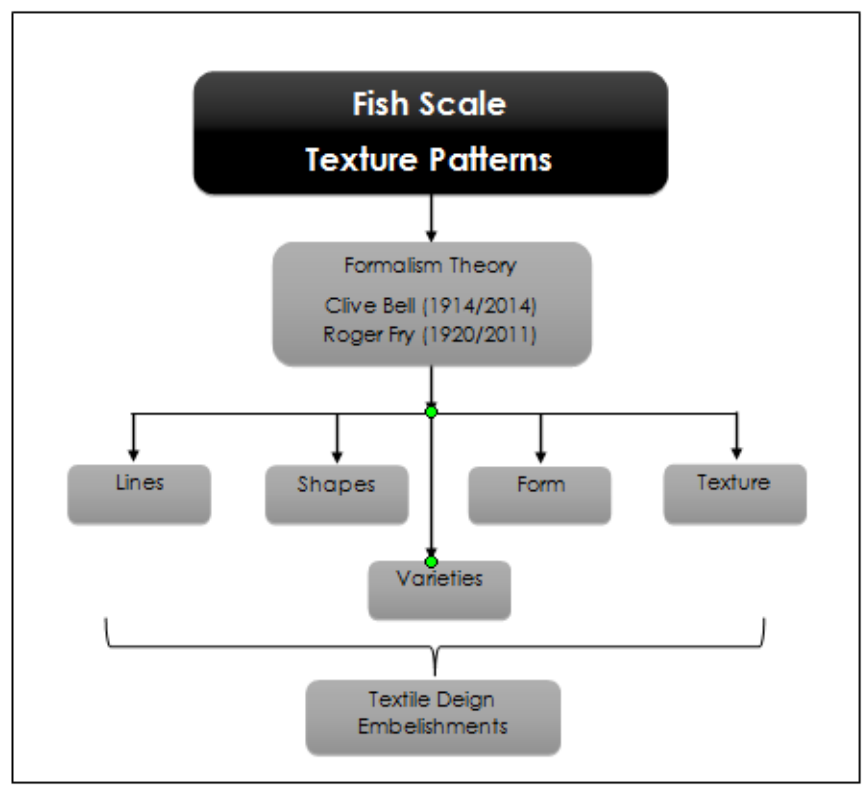

Fig. 1 Theoretical framework for fish scale texture patterns.

\section{RESEARCH METHODOLOGY}

Detailed explanation of each approach taken in this research is discussed in the following sections; description of the methodology, research sites, subjects/samples, instruments, research process and data analysis. This research study that investigates the quality of the material is referred to as qualitative research. One of the approaches to qualitative study is a case study. This is because the objects of the research are treated as cases by researcher. The researcher studied multiple cases at the same time as part of one overall study. The sampling used in this study was purposeful sampling based on the researcher's selection to investigate the study.

The subjects were four selected fish scales namely Thread Fish Bream, Herring, John Snapper and Malabar Red Snapper (Refer to Table 1) were purposefully selected for this research. The research site for this study included wet market, tesco and wholesale market. These four types of fish are Malaysia's favorite species used in cooking. In the past fish scales are found to be waste material.

The researchers collected the waste from these fishes to be used as a study material.Researchers can obtain 16 to 20 kilograms a day from each fish store every day. These distinct kinds and quality of scales have been recognized from John's Snapper or Golden Snapper "Jenahak," Threadfish Bream "Kerisi," Malabar Red Snapper "Merah" and Herring or "Terubok" fish. 


\section{THE AESTHETIC OF FISH SCALE TEXTURE PATTERNS AS TEXTILE \\ DESIGNS EMBELLISHMENTS}

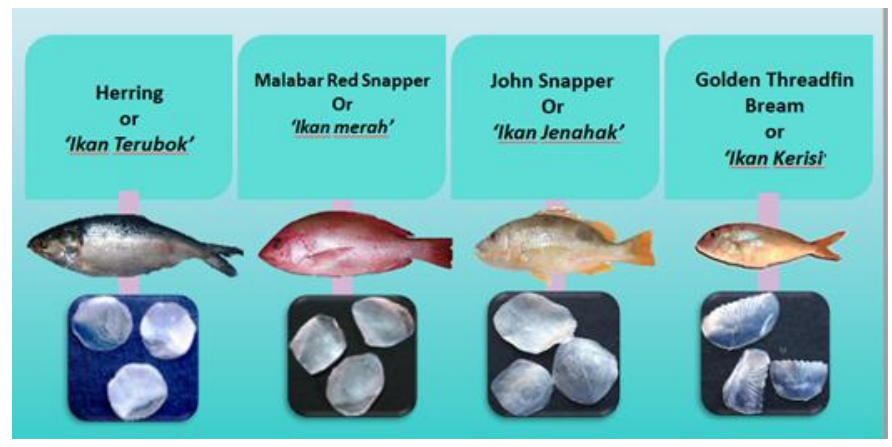

TABLE I: VISUAL APPEREANCE OF PRODUCT

The instruments involved in collecting the needed data were field notes, documents and visual materials. Based on the observation, this fish scale has plastic characteristics. The scales of the fish are light and bright.The fine-grained surface of the scales has formed an attractive link on the surface of the fish scales while the shape.

Due to its natural nature such as plastic, the fish has drawn its attractiveness, giving researchers an idea to create fish scales as an ornamental material. The scrambled fish is also defined by its beauty, size and density as the decoupling material discovered on the market.

\section{DATA ANALYSIS}

(a) The Study of Fish scale

The four different types of fish scales being researched had proven to be of different sizes, forms and textures. The Malabar Red Snapper and john snapper has the thickest scales. The John Snapper or 'Ikan Jenahak' has a texture that looks like fingerprint and the scales of Herring has an interesting surface. It has contour lines. Its scales are also attractive because the edge will produce furry lines after the drying process.Fish scales are waste material that is highly valuable and attractive because different types of fish have different surface bonds.

(b) The use of fish scales as textile embellishments

To identify the durability of these fishes, it can be used as a embellishment material, thus the researcher used sewing machine to sew the fish scales. Proven outcomes that after sewn

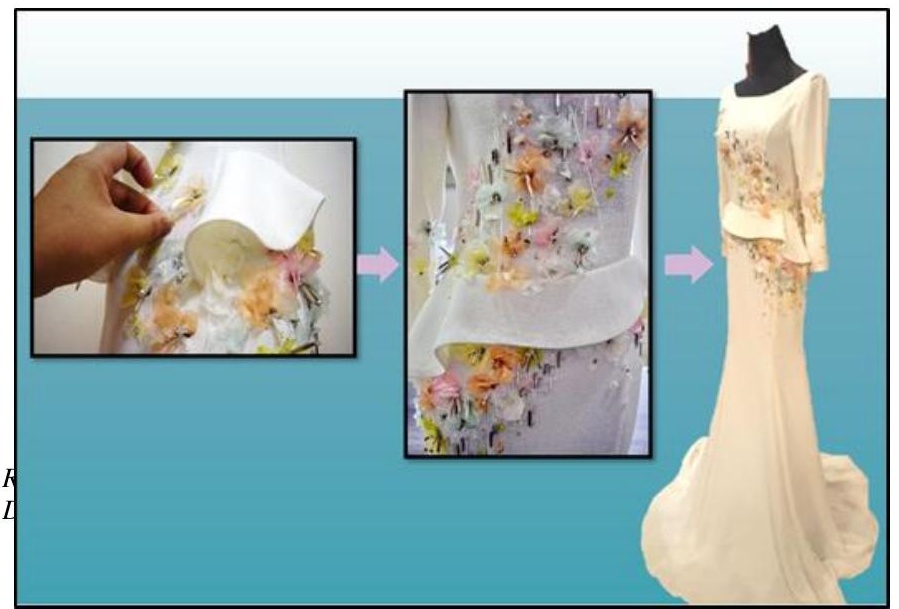

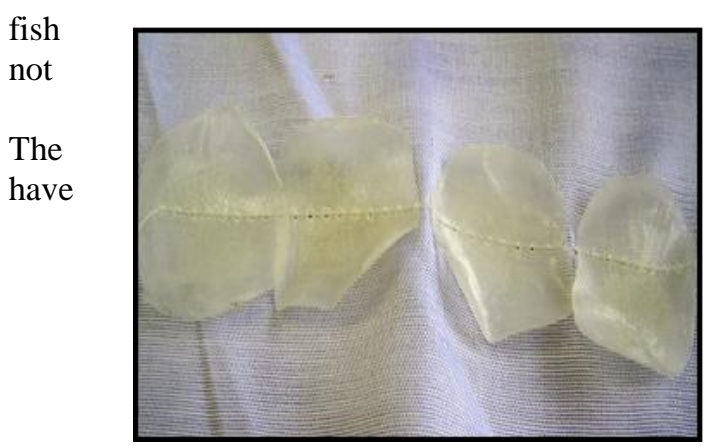

scales are broken or harmed. fish scales amazing

characteristics such as plastic fish scales that are simple to shape and not easily crushed.

Fig. 2 The fish scales were pliable; can be bent or flexed without breaking

Based on the image of the women's clothing below (Refer to Figure 3, fashion designers were inspired to use fish scales for textile surface embellishment. Fashion designers create their designs according to the arrangement of designs that are needed. Fish scales are natural material that has quality similar to other ornamental products on the market.

Fig. 3 Women's dress are decorated with scales of fish.

Natural material sources are more user friendly than non-natural or synthetic products (Overvliet, K.E., \& Soto-Faraco, S., 2011; Rozin, P., 2005). This can be seen in food intake, in the production of medicinal products and cosmetic (Sheila, M.M., Godeliver, A. K., \& Fatuma, F., 2014). It shows that consumers around the world believes more in the use of natural products in their daily life.

\section{CONCLUSION}

Fish scales also have their own unique characteristics. They can be smooth and flat when water is spread over and become hard and rolled under the sunshine. Then the fish scales will be smooth again when water is spread over and vice versa.

Structure to be as advancement material for diverse application. Surprisingly, this material has received little attention from the materials development and the art community. Experimental measurements are available to adapt this material as it involves significant issues of individual perception and aesthetic appreciation of the material to be as a substitute material in surface design.

In fact, there is a wide variety of different types of fish scale characteristic in nature, making the study of such materials a challenging task very few structures and limitation of aesthetic characteristic in nature, making the

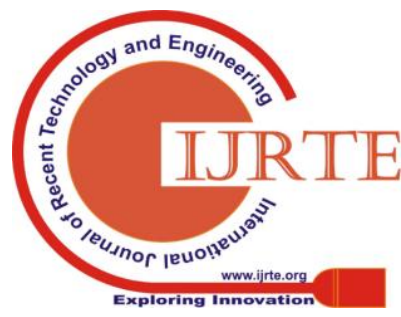




\section{THE AESTHETIC OF FISH SCALE TEXTURE PATTERNS AS TEXTILE DESIGNS EMBELLISHMENTS}

study of such a challenging task.

Basically, the fields of product design and textiles are similar in terms of the use of a product development idea. Textile designers or fashion designers have the privilege of looking at the process of producing a product. This is because the fashion and textile designers are responsible towards the choosen materials and process for the product designed.

\section{REFERENCES}

(Periodical style)

[1] Braembussche, A.V. (2009). Thinking art: An introduction to philosophy of art. New York: Springer.

[2] Bell, C. (2014). Art. New York: CreateSpace Independent Publishing Platform. (Original work published 1914)

[3] Fry, R. (2011). Vision and design. United States: Dover Publications. (Original work published 1920)

[4] Hekkert, P. (2006). Design aesthetics: Principles of pleasure in design. Psychology Science, 48, 157-172.

[5] Overvliet, K.E., Karana, E., \& Soto-Faraco, S., (2015). Material and Design. Perception of Naturalness in Textiles.

[6] Overvliet, K.E., Karana. E., \& Soto-Faraco, S. (2011). I Can't Believe This Isn't Wood! An Investigation In The Perception Of Naturalness. Acta psychologica, 136(1), 95-111.

[7] Rozin, P. (2005). The Meaning Of "Natural": Process More Important Than Content. Psychological Science, 16(8), 652-658.

[8] Rozin, P., Spranca, M., Krieger, Z., Neuhaus, R., Surillo, D., Swerdlin, A., et al. (2004). Preference For Natural: Instrumental And Ideational/Moral Motivations, And The Contrast Between Foods And Medicines. Appetite, 43(2), 147-154.

[9] Sheila M. M., Godeliver A. K, \& Fatuma F. (2014). Documentation and Phytochemical Screening of Traditional Beauty Products Used in Missenyi District of Tanzania. Journal of Cosmetics, Dermatological Sciences and Applications, 2014, 4, 355-364.

(All authors should include biographies with photo at the end of regular papers.)

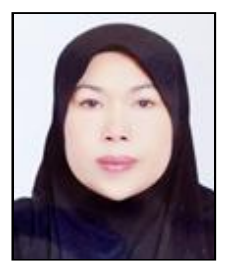

First A. Author Rusmawati GHAZALI holds an undergraduate and postgraduate degree in Textile Design from the prestigious University Technology Mara (UiTM), Malaysia. Currently, she is involved in teaching at the textile design department and holds a position as a Senior Lecturer specializing in the area of Textile Design and Batik Design. She is also an active scholar involved in various researches at both local and international seminars and academic conferences. Her research focuses both in textile design, batik design and as well as visual arts education. She is pursuing her doctorate in the area of textile surface and embellishment from natural sources.

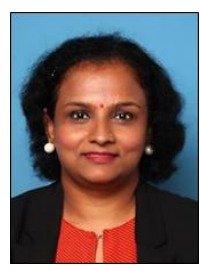

Maithreyi SUBRAMANIAM is currently teaching in several private insitutions, received both her M.Ed. and Ph.D. degrees in the field of Art Education from the most prestigious University of Malaya, Malaysia. She was also awarded the University Malaya's excellence award for outstanding achievement in

the category of $\mathrm{Ph} . \mathrm{D}$. completion period more than 3 years but less than 4 years, 2017. She has over 12 years of teaching experience specializing in graphic design and art education. She has published original articles in the finest journals in the area of her studies. Her research interest includes teaching, learning, evaluation and psychology in art education. She is a life member of Association for Development of Teaching, Education and Learning, India.

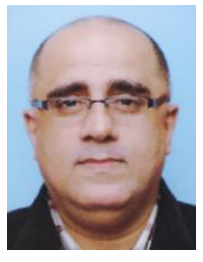

Associate Prof. Dr. Sabzali MUSA KAHN was born in Besut, Terengganu, Malaysia. He graduated with a degree in visual arts from Universiti Sains Malaysia, Penang. He then pursued his Masters in Education from Universiti Putra Malaysia and Doctorate (Ph.D) in Architecture Studies from Universiti Putra Malaysia. He started his career as a consultant in government and corporate sectors. His participation in various major exhibitions organized by universities, galleries, State and National Art Gallery has greatly enhanced his knowledge and experience as an artist. He is also involved with visual arts research, theatre and workshops in the aspect of creative teaching for the pre-school children, people with disabilities and in curriculum development of visual art studies at the university level. Currently, he is the Senior Lecturer at Academy of Malay Studies, University of Malaya, Kuala Lumpur, Malaysia.

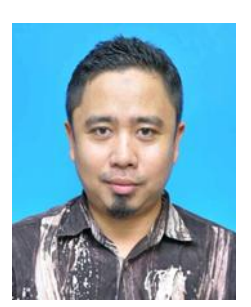

Rainal Hidayat WARDI (Ph.D) is a Senior Lecturer in Textile Design Department, Faculty of Art \& Design, Universiti Teknologi MARA, Malaysia. He started his Bachelor of Art \& Design in Universiti Teknologi MARA Malaysia, specializing in Textile Design, traditional Batik and Weaving (1993-1997). He furthered his Master of Textile Design at De Monfort University, Leicester (1999 - 2001) specializing in Traditional Batik \& Weaving and Doctor of Philosophy in University of Malaya, Malaysia in 2015. Currently he is a full time lecturer at Universiti Teknologi MARA for 19 years. His specialization is focusing on Traditional Batik and Weaving, Textile CAD/CAM, Design Thinking, User Centered Design and Textile Design Process. Holding a Certified Professional Technologist by Malaysia Board of Technologists (MBOT) in 2017 has expands his professional practice to Technical and Vocational education.

Published By:

Blue Eyes Intelligence Engineering \& Sciences Publication

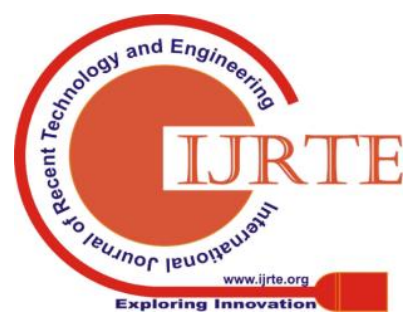




\section{THE AESTHETIC OF FISH SCALE TEXTURE PATTERNS AS TEXTILE DESIGNS EMBELLISHMENTS}

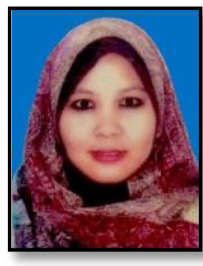

Borned in Penang, in a position as a Senior Lecturer, Irma Murni ISMAIL from Art Trivium Department currently teaching a Fundamental Drawing at the Universiti Teknologi Mara (UiTM), Shah Alam, Malaysia. She also holds an undergraduate and postgraduate degree in Textile Design includes her past experiences in teaching Weaving (Fiber Arts), Batik and Textile Designs. She completed her degree studies at Universiti Teknologi MARA Malaysia (Uitm) and awarded a Bachelor of Textile Design, majoring in Weaving and Traditional Batik Design, 1993-1997. She furthered her MA in Textile Design in 2003, specializing in Papier Mache as Fiber Arts. Besides teaching, Irma also is an active artist that pursue her producing various artworks thus involved her in Solo Exhibition.

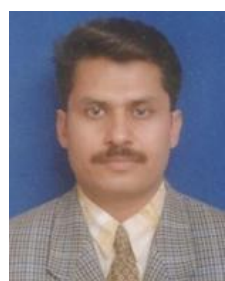

Syed Muhammad Ahmad SHERAZI received his BA (Hons) and MA degrees in the field of textile technology from the prestigious University of Engineering and Technology, Lahore, Pakistan. He is also involved in business and investment field and an independent scholar in the art and design field, Malaysia. He is actively involved in providing talks and seminars focusing on community service in Malaysia. 